\title{
Risk Analysis of Mortality Improvement: The Case of Chinese Annuity Markets
}

\author{
Hong $\mathrm{Mao}^{\mathrm{a}}$, Krzysztof M. Ostaszewski ${ }^{\mathrm{b}}$ and Yuling Wang ${ }^{\mathrm{c}}$ \\ ${ }^{a}$ Business School, Shanghai Second Polytechnic University, No. 50, Yuan Ming Yuan Road, Shanghai, \\ 200002, China. \\ E-mail: hmaoi@online.sh.cn \\ ${ }^{\mathrm{b}}$ Department of Mathematics, Illinois State University, Campus Box 4520, William Hall 315E, Normal, IL \\ 61790-4520, U.S.A. \\ E-mail: krzysio@ilstu.edu \\ ${ }^{\mathrm{c}}$ Department of Risk Management and Insurance, Real Estate and Business Law, Florida State University, \\ Tallahassee, Florida 32306, USA. \\ E-mail: yw04c@garnet.acns.fsu.edu
}

China has experienced significant improvement in longevity (commonly referred to as mortality improvement) since the late 1930s. The rate of mortality improvement has been faster than in most developed countries. This development has resulted in a great challenge to provide retirement income to the ageing population. This challenge is increased by the increasing presence of commercial annuity products in China. Such products should become an important source of retirement benefits. In this article, we propose a model of mortality improvement and calculate its factors using Chinese life tables. We also analyze the risks to annuity providers due to mortality improvement, and compare risks of mortality improvement for two different forms of annuities: equity-linked annuity and traditional fixed annuity. Finally, we provide several suggestions for managing risks of mortality improvement. In particular, we discuss a natural hedging strategy of issuing variable annuity instead of traditional annuity.

The Geneva Papers (2008) 33, 234-249. doi:10.1057/gpp.2008.4

Keywords: mortality improvement; equity-linked annuity; risk management

\section{Introduction}

There has been an increased interest among scholars in the topic of forecasting mortality. Generally, past mortality trends provide the basis for forecasting mortality improvement. Let us be more specific about the concepts of mortality improvement and mortality improvement risk. Mortality improvement refers actually to longevity improvement, that is, the situation that the ratio of death rates between two adjoining years reduces. Mortality improvement risk is the risk that life annuity product may be priced based on past projection of mortality, which turns out to be inadequate because of unexpected rates of mortality improvement.

A number of scholars have studied mortality improvement. ${ }^{1}$ Lin et al. ${ }^{2}$ discussed the trends of ageing, analyzed the contribution of the growth of life expectancy of each age

\footnotetext{
${ }^{1}$ Keyfitz (1991), Lee (1998), Olshansky (1988), Pollard (1987), Tabeau et al. (2001), Andreev and Vaupel (2005)

${ }^{2}$ Lin et al. (2003)
} 
between consecutive life tables, compared causes in the contribution of improvement in mortality of different age groups on life expectancy at age 0 between two consecutive life tables, and used the estimated mortality improvement models to evaluate the annuity pricing under cohort life tables. Willets ${ }^{3}$ identified the phenomenon of "select birth cohorts", MacMinn et al. ${ }^{4}$ further studied the actual structure of such cohorts, the correlation among them in various countries, and their impact on the prices of retirement annuities. Cairns et al. ${ }^{5}$ discussed how to reveal the price of the risk of mortality improvement with the use of longevity bonds, also termed survivor bonds. MacMinn et al. ${ }^{6}$ discussed survivor bonds and their potential role in pricing and development of the annuity market.

The existing literature helps us establish a model of mortality improvement, and calculate factors to reduce mortality improvement risk using Chinese, life tables. We also analyze the risks associated with mortality improvement, and compare two different annuity insurance types: equity-linked annuity insurance and traditional annuity insurance. Finally, we discuss the strategy to manage mortality improvement risk with issuing annuities of some guaranteed death benefits.

\section{Chinese mortality improvement}

The Chinese population has been experiencing unprecedented growth in individual life span in the latter part of the 20th century. With the development of technology, especially medical and pharmaceutical, and the resulting improvement of medical care as well as improved living standards, life expectancy will continue to improve. Figure 1 shows the life expectancy in China between 1935 and 2006. It exhibits an almost linear trend. It may slow down or may just pick up this linear trend in the future. ${ }^{7}$ Compared with other Asian countries and regions, mortality improvement in mainland China lagged far behind that of Japan, Hong Kong and Taiwan in the early 1950s, but the progress has been remarkable. Life expectancy at birth in mainland China increased from 48 years in the early 1950s (roughly at par with that of the United States at the beginning of the twentieth century) to 57 years in the early $1960 \mathrm{~s}$, rose further to 64 in the early 1970s, and now stands at 72 years, a level which is well above the average for Asia and the world as a whole. ${ }^{8}$ Comparing the Chinese Life Table (1990-1993) with the Life Table (2000-2003), we can see that the average death rate of the insured population of China decreased 30 per cent only in ten years.

As the population of China is ageing, Chinese consumers will pay more attention to retirement benefits products, China's social insurance retirement program covers approximately 40 per cent of city workers, and only about 5.8 per cent of farmers, as of 2003. It should be noted that China's population stands at approximately 1.3

\footnotetext{
${ }^{3}$ Willets $(1999,2004)$

${ }^{4}$ MacMinn et al. (2005)

${ }^{5}$ Cairns et al. (2005)

${ }^{6}$ MacMinn et al. (2006)

${ }^{7}$ see Oeppen and Vaupel (2002)

${ }^{8}$ Zhao and Kinfu, 2005
} 


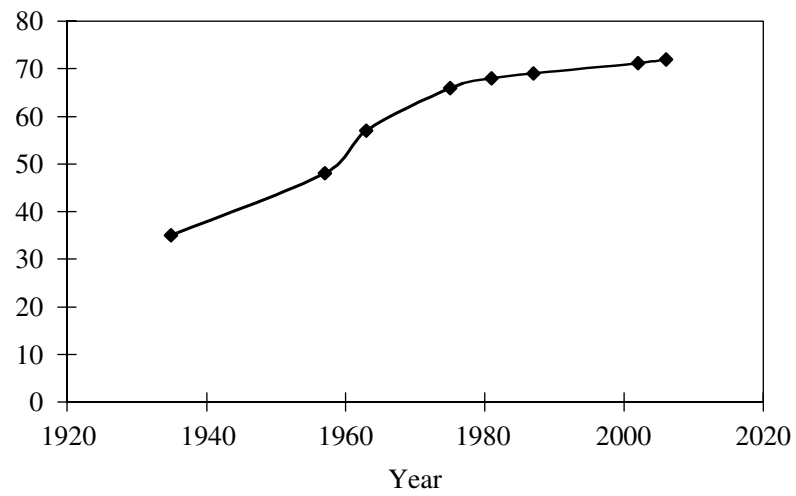

Source: China's State Bureau of Statistics (2006).

Figure 1. Life expectancy at birth in China (1935-2006). Source: China's State Bureau of Statistics (2006).

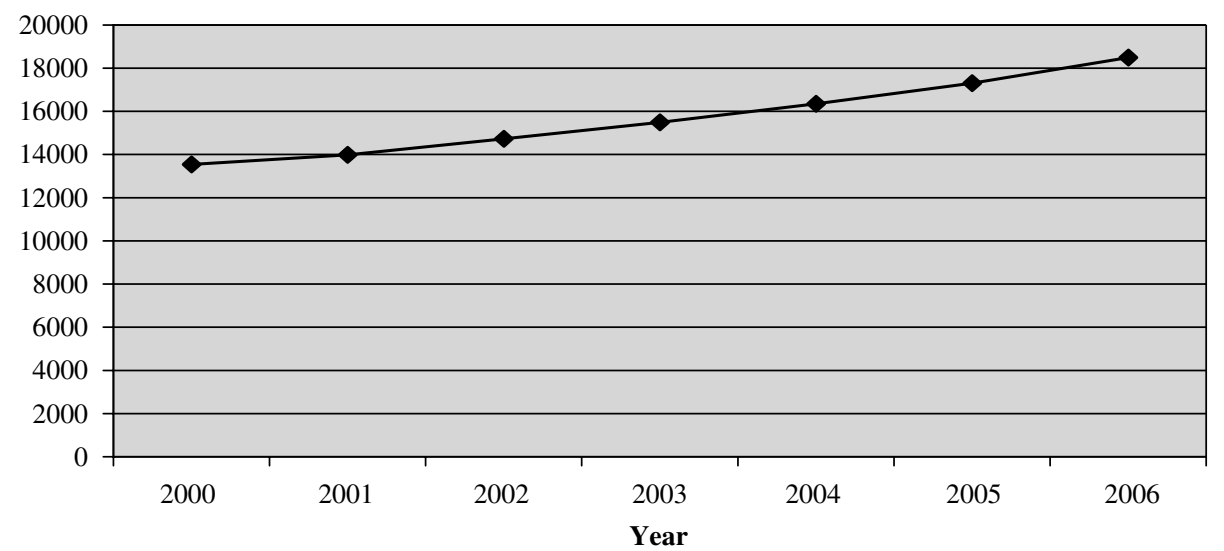

Figure 2. Population involved in retirement benefit insurance in China (Per 10,000) (2000-2006). Source: www.gov.cn.

billion, with 80 per cent living in the countryside. We also should note that while social insurance offers wider coverage to urban Chinese workers, longevity risk is more serious in the countryside. In 2000, the population aged over 65 represented 7.7 per cent of the rural population, and only 6.1 per cent of the urban population of China. As most of the rural population is not covered by any form of retirement insurance, this population represents a potentially lucrative market. On the other hand, about 140 million young workers from the countryside are working in Chinese cities. Their employers rarely offer any retirement benefits. Those workers may also turn to individual insurance products when their incomes grow to a satisfactory level, and the need for retirement income becomes a higher priority for them. China's family structure may also create opportunities for commercial insurance programs. The 
central government's "One-Child Policy" has led to smaller families, putting more of the burden of caring for the elderly on each young person. Figure 2 illustrates the gradual increase in enrollment in retirement benefit insurance plans in China since 2000. In 2006, about 15 per cent of the whole population were involved in some form of retirement insurance plans. The income spent on annuity insurance was about RMB431 per person. It was only about 10 per cent of international average level and 1/70 of America. The potential market for retirement products is substantial.

Longer life expectancy will draw people's attention to retirement benefit products, and increase interest in private insurance products, while putting pressure on both the social insurance systems and the life insurance industry, not just because of greater costs, but also due to greater uncertainty. Especially for China's social insurance system with its pay-as-you-go structure, substantial funding challenge is looming on the horizon for the time when the children of the "One-Child Policy" are expected to support their parents' generation retirement.

In China, men are required to retire at age 60 and women at 55. Some scholars suggest extending the retirement age. But China also has unemployment problems, and policymakers often believe (wrongly, in our opinion) that retiring workers should give up their employment spots for young workers joining the labor market. Such belief, while common among political decision makers, completely ignores the effect of this intergenerational "replacement process" on the aggregate demand, and aggregate supply, in the national economy. Retiring workers have typically higher skills, higher incomes, and higher consumption levels than younger workers replacing them. If the skills of the younger workers are insufficient (and they usually are), replacement may not be possible. In general, replacement of experienced skilled workers by younger, inexperienced ones, leads to lower productivity, resulting in lower wages, lower profits, and declining investment. But these supply-side effects may turn out to be minimal when compared to the demand-side problems. If the retiring workers receive retirement benefits that are lower than their incomes prior to retirement, and are uncertain of the sustainability of those retirement benefits, the resulting decrease in their consumption may substantially reduce national aggregate demand, resulting in the disappearance of the employment positions they vacated.

Commercial insurance products may be good sources of supplementary retirement income and may reduce the uncertainty of income of retirees. The Chinese government encourages local insurance companies to create new products to meet this need and plans to gradually open the door to foreign insurance companies. We can expect substantial market growth for retirement products in the early 21 st century in China. But the risk of mortality improvement must be addressed by policy makers and industry leaders.

The issue of mortality improvement has received increased attention in scholarly literature recently. A recent issue of Journal of Risk and Insurance (December, 2006) explores public policy and market issues concerning longevity risk. For example: who should bear the longevity risk? Should a mortality-linked financial instrument be used to hedge this risk? But existing literature is mostly concerned with the cases of the United States or the United Kingdom and to a lesser degree with other developed economies. As most of the developed countries have already set up complete systems of social security and commercial insurance programs, the suggestions and discussions may not be appropriate for the cases in the developing countries. Mortality improvement risks 
Table 1 Mortality reduction factors using Chinese life tables

\begin{tabular}{llr}
\hline Age & \multicolumn{2}{c}{$\begin{array}{c}\text { Reduction factors } \\
(k=10)\end{array}$} \\
\cline { 2 - 4 } & Female & Male \\
\hline 60 & 0.5340 & 0.5871 \\
65 & 0.5875 & 0.6340 \\
70 & 0.6416 & 0.6811 \\
75 & 0.7034 & 0.7388 \\
80 & 0.7805 & 0.8111 \\
\hline
\end{tabular}

affect all forms of retirement income provision, but governments can view private systems as a diversification mechanism for the risk they face themselves.

\section{Model of mortality improvement and calculations of mortality reduction factors}

A mortality improvement model we propose is:

$$
q_{x}(t+k)=q_{x}(t) R_{x}(t+k)
$$

where $q_{t}(t)$ is the death probability of the insured aged $x$ at the year of $t, R_{x}(t+k)$ is a mortality reduction factor at time $(t+k)$ and $q_{x}(t+k)$ is the death probability of the insured aged $x$ at the year of $(t+k)$

One of the methods of determining the mortality reduction factor is extrapolation of a log-linear trend in death rates. Death rate at each age is assumed to decline with time, and luture death rates arc forecasted by some recent trends of such decline. ${ }^{9}$ We assume

$$
\ln q_{x}(t+k)=\alpha(x)+\beta(x)(t+k)
$$

so that

$$
q_{x}(t+k)=e^{\alpha(x)+\beta(x)(t+k)}
$$

The reduction factor can be derived as:

$$
R_{x}(t+k)=\frac{q_{x}(t+k)}{q_{x}(t)}=\frac{e^{\alpha(x)+\beta(x)(t+k)}}{e^{\alpha(x)+\beta(x) t}}=e^{\beta(x) k}
$$

With the help of mortality tables, we can determine the values of parameter $\beta(x)$ and then we can determine the values of reduction factors $R_{x}(t+k)$.

Table 1 shows the reduction factors calculated using Equation (4) for selected ages $(x)$ and time $(k=10)$ ahead of the base year 2003 based on Chinese Life Tables. Table 1 indicates the decreasing effect of mortality improvement as age increases. We note that females have lower reduction factors than males.

\footnotetext{
${ }^{9}$ Andreev and Vaupel (2005)
} 


\section{Risk analysis of mortality improvement}

In this section, we use equity-linked life annuity as an example to analyze the change of annuity value when considering mortality improvement for both female and male cases. To simplify our analysis, we assume the risk-free interest rate $r$ is constant during a policy period. We also assume the premium is paid in the form of a single premium. We define

$U=\quad$ Single benefit premium of equity-linked annuity insurance without consideration for mortality improvement

$U I=\quad$ Single benefit premium of equity-linked annuity insurance with consideration for mortality improvement

$U^{(1)}=$ Single benefit premium of traditional annuity insurance without consideration for mortality improvement

$U I^{(1)}=$ Single benefit premium of traditional annuity insurance with consideration for mortality improvement

$T=\quad$ Term of insurance contract, in years

$D=\quad$ Value of investment in a reference fund at time 0 , with the reference fund assumed to have no dividend yield

$D_{i}=\quad$ Value of investment in a reference fund at time $i$, with the reference fund assumed to have no dividend yield

$r_{g}=\quad$ minimum guaranteed rate of return

${ }_{i} p_{x}=$ probability that a life-age $(x)$ is still alive $i$ years hence

$q_{x}=\quad$ Mortality rate for an individual aged $x$

$\sigma=\quad$ Standard deviation of cumulative investment

$\sigma_{i}=\quad$ Standard deviation of cumulative investment at time $i$.

The guarantee options are assumed to be European for each sub-period, with initial investment of $D$. Under these assumptions, the market price for the single premium is

$$
U=\sum_{i=1}^{T} \max \left(D_{i}, D e^{r_{g} i}\right)_{i} p_{x} e^{-r i}
$$

where the variable $D_{i} / D$ investment return rate at time $i$ is assumed to follow the log-normal distribution with mean $\mu$ and variance $\sigma_{i}^{2}$. Using the Black-Scholes option pricing model, we obtain the following closed-form solution for the single premium: ${ }^{10}$

$$
U=\sum_{i=1}^{T}{ }_{i} p_{x} D e^{\left(r_{g}-r\right) i}\left(1-\Phi\left(B_{i}\right)\right)+D \sum_{i=1}^{T}{ }_{i} p_{x} \Phi\left(A_{i}\right)
$$

\footnotetext{
${ }^{10}$ Bacinello and Orut (1993) discussed pricing equity-linked life insurance and we here extend it to the case of annuity.
} 
The Geneva Papers on Risk and Insurance - Issues and Practice

240

Table 2 Relative payment risk for equity-linked annuity (Male and Female)

\begin{tabular}{|c|c|c|c|c|c|c|c|c|}
\hline$r=$ & 0.01 & 0.02 & 0.03 & 0.04 & 0.05 & 0.06 & 0.08 & 0.10 \\
\hline \multicolumn{9}{|c|}{$D=1, x=60, t=2003, r_{g}=0.03, T=40$ (Female) } \\
\hline$\sigma=0.1$ & 0.2460 & 0.2206 & 0.2033 & 0.1942 & 0.1910 & 0.1907 & 0.1917 & 0.1923 \\
\hline 0.2 & 0.2482 & 0.2264 & 0.2104 & 0.1996 & 0.1932 & 0.1899 & 0.1884 & 0.1894 \\
\hline 0.3 & 0.2504 & 0.2300 & 0.2144 & 0.2031 & 0.1953 & 0.1904 & 0.1863 & 0.1861 \\
\hline 0.4 & 0.2509 & 0.2313 & 0.2159 & 0.2044 & 0.1961 & 0.1904 & 0.1846 & 0.1833 \\
\hline 0.5 & 0.2499 & 0.2307 & 0.2156 & 0.2040 & 0.1954 & 0.1894 & 0.1827 & 0.1806 \\
\hline 0.6 & 0.2478 & 0.2290 & 0.2140 & 0.2025 & 0.1938 & 0.1876 & 0.1805 & 0.1780 \\
\hline 0.7 & 0.2452 & 0.2266 & 0.2118 & 0.2004 & 0.1917 & 0.1854 & 0.1781 & 0.1755 \\
\hline 0.8 & 0.2424 & 0.2240 & 0.2094 & 0.1980 & 0.1894 & 0.1831 & 0.1758 & 0.1730 \\
\hline \multicolumn{9}{|c|}{$D=1, x=60, t=2003, r_{g}=0.03, T=40$ (Male) } \\
\hline$\sigma=0.1$ & 0.2593 & 0.2335 & 0.2159 & 0.2065 & 0.2031 & 0.2026 & 0.2036 & 0.2042 \\
\hline 0.2 & 0.2620 & 0.2398 & 0.2235 & 0.2124 & 0.2057 & 0.2021 & 0.2002 & 0.2011 \\
\hline 0.3 & 0.2647 & 0.2439 & 0.2280 & 0.2163 & 0.2082 & 0.2030 & 0.1893 & 0.1978 \\
\hline 0.4 & 0.2656 & 0.2455 & 0.2298 & 0.2179 & 0.2092 & 0.2032 & 0.1968 & 0.1950 \\
\hline 0.5 & 0.2647 & 0.2452 & 0.2297 & 0.2177 & 0.2088 & 0.2023 & 0.1950 & 0.1924 \\
\hline 0.6 & 0.2627 & 0.2435 & 0.2282 & 0.2163 & 0.2073 & 0.2006 & 0.1928 & 0.1898 \\
\hline 0.7 & 0.2600 & 0.2411 & 0.2260 & 0.2141 & 0.2051 & 0.1985 & 0.1904 & 0.1871 \\
\hline 0.8 & 0.2571 & 0.2384 & 0.2235 & 0.2117 & 0.2028 & 0.1961 & 0.1880 & 0.1846 \\
\hline
\end{tabular}

where $\Phi$ is the cumulative distribution function of a standard normal probability distribution, and

$$
\begin{aligned}
A_{i} & =\frac{\ln \left(e^{-r_{g} i}\right)+\left(r+12 \sigma^{2}\right) i}{\sigma \sqrt{i}}, \\
B_{i} & =A_{i}-\sigma \sqrt{i} \\
{ }_{i} p_{x} & =\prod_{k=1}^{i}\left(1-q_{x+k}(t)\right)
\end{aligned}
$$

In order to consider mortality improvement, we let ${ }_{i} p_{x}(t+k)$ be the survival probability using cohort life table with base year $t$. Then

$$
{ }_{i} p_{x}(t+k)=\prod_{k=0}^{i}\left(1-q_{x+k}(t+k)\right)
$$

The single premium of equity-linked annuity considering mortality improvement can be calculated as

$$
\begin{aligned}
U I= & \sum_{i=1}^{T}{ }_{i} p_{x}(t+k) D e^{\left(r_{g}-r\right) i}\left(1-\Phi\left(B_{i}\right)\right) \\
& +D \sum_{i=1}^{T} i{ }_{i}(t+k) \Phi\left(A_{i}\right)
\end{aligned}
$$

$U I-U$ is the difference between the corresponding annuity values, which can be seen as the absolute payment risk faced by insurance companies due to mortality improvement and $U I-U / U$ can be seen as relative payment risk. 


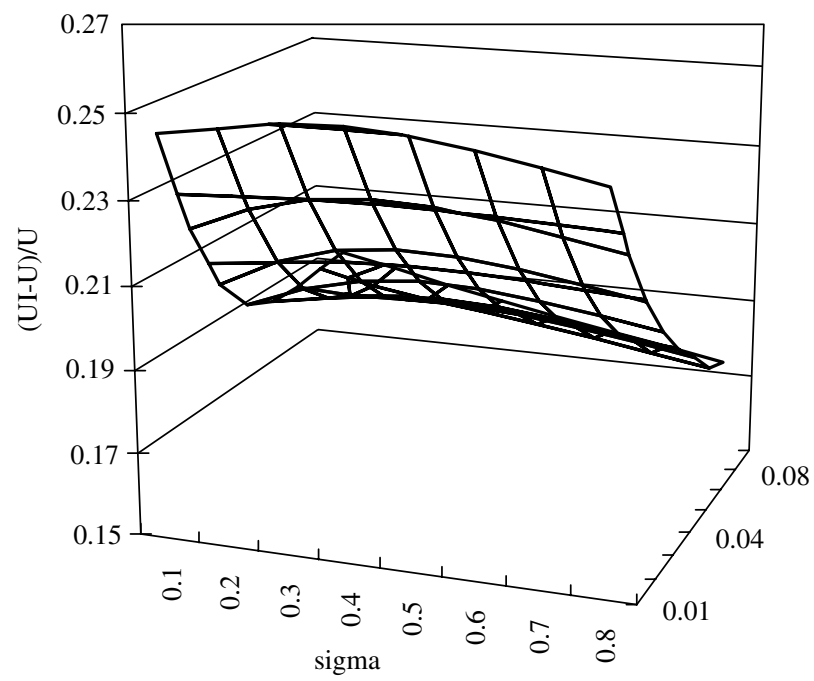

Figure 3. Relative payment risk for equity-linked annuity under different interest rates and different standard deviations (Female). Assumptions: $D=1, x=60, t=2003, r_{g}=0.03, T=40$.

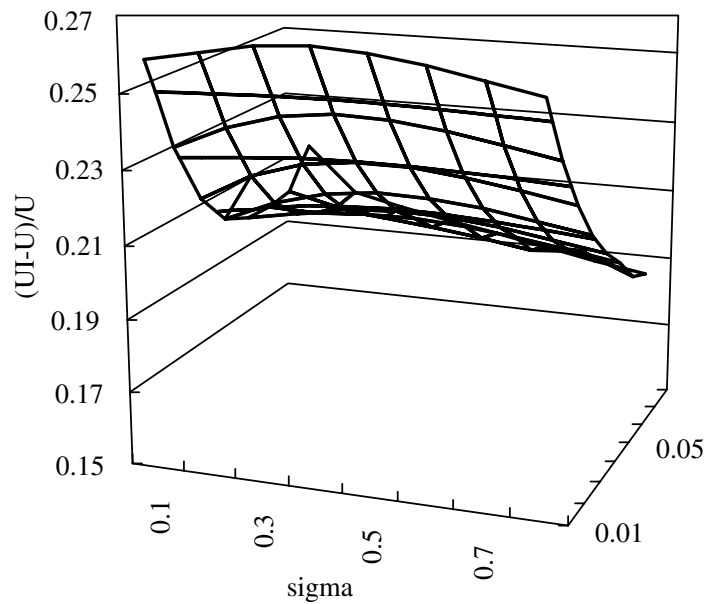

Figure 4. Relative payment risk for equity-linked annuity under different interest rates and different standard deviations (Male). Assumptions: $D=1, x=60, t=2003, r_{g}=0.03, T=40$.

Table 2 calculates the relative payment risks for equity-linked annuity with the changes of the risk-free interest rates and investment standard deviations for both male and female cases. When the risk-free interest rate rises above 8 per cent, there are very small effects of mortality improvement on annuity values when the risk-free interest rate changes. We see this in both male and female cases. The relative risks increase when the standard deviation increases from 0.1 to 0.4 , and then they decrease when the standard deviation increases from 0.4 to 0.8 . This pattern occurs in both the 
The Geneva Papers on Risk and Insurance - Issues and Practice

Table 3 Relative payment risks with three stochastic variables (Male)

\begin{tabular}{|c|c|c|c|c|c|c|c|c|}
\hline & $r$ & $r_{g}$ & $\sigma(<0.5)$ & {$[U I-U] / U$} & $r$ & $r_{g}$ & $\sigma(\geqslant 0.5)$ & {$[U I-U] / U$} \\
\hline 1 & $1(0.02)$ & $1(0.06)$ & $1(0.09)$ & 0.3283 & $1(0.02)$ & $1(0.06)$ & $1(0.50)$ & 0.3174 \\
\hline 2 & 1 & $2(0)$ & $2(0.12)$ & 0.2034 & 1 & $2(0)$ & $2(0.53)$ & 0.2084 \\
\hline 3 & 1 & $3(0.03)$ & $3(0.15)$ & 0.2368 & 1 & $3(0.03)$ & $3(0.56)$ & 0.2443 \\
\hline 4 & $2(0.05)$ & 1 & 2 & 0.2348 & $2(0.05)$ & 1 & 2 & 0.2448 \\
\hline 5 & 2 & 2 & 3 & 0.2018 & 2 & 2 & 3 & 0.1937 \\
\hline 6 & 2 & 3 & 1 & 0.2030 & 2 & 3 & 1 & 0.2088 \\
\hline 7 & $3(0.08)$ & 1 & 3 & 0.2041 & $3(0.08)$ & 1 & 3 & 0.2080 \\
\hline 8 & 3 & 2 & 1 & 0.2045 & 3 & 2 & 1 & 0.1921 \\
\hline 9 & 3 & 3 & 2 & 0.2029 & 3 & 3 & 2 & 0.1944 \\
\hline I & 0.2561 & 0.2557 & 0.2453 & & 0.2567 & 0.2567 & 0.2394 & \\
\hline II & 0.2132 & 0.2036 & 0.2137 & & 0.2157 & 0.2031 & 0.1980 & \\
\hline III & 0.2038 & 0.2142 & 0.2142 & & 0.1981 & 0.2158 & 0.2098 & \\
\hline $\mathrm{R}$ & 0.0524 & 0.0521 & 0.0316 & & 0.0586 & 0.0536 & 0.0414 & \\
\hline
\end{tabular}

Assumptions: $D=1, x=60, t=2003, T=40$.

male and female case. To make things clearer, we illustrate the relative payment risks for equity-linked annuities where we consider all combinations of the parameter $r$ and $\sigma$ using a three-dimensional diagram (see Figures 3 and 4). Compared with Table 1, females have less relative payment risks for equity-linked annuity than males for the insurance company.

High risk-free interest rate reduces insurers' payment risk and also discourages the consumer from buying an annuity. When risk-free interest rate is well above guaranteed minimum interest rate, the insurers' investment risk will be minimal and the risk left is mostly mortality improvement and anti-selection (as some annuitants may drop from the pool). ${ }^{11}$ Currently interest rates in China are at historically low levels, so the dual effects of low interest rate and mortality improvement will make paying guaranteed payments more difficult and risky for insurance companies. Insurance companies also need to evaluate the effects of volatility of investment returns on annuity values.

The above model analyzes the effects of mortality improvement on annuity values with two parameters (risk-free interest rate and standard deviation) changing simultaneously. Next, we will carry out risk analysis of mortality improvement with several parameters changing simultaneously. The parameters considered are the riskfree interest rate $(r)$, minimum guaranteed return rate $\left(r_{g}\right)$, and volatility of investment $(\sigma)$. Figure 4 illustrates the effects of mortality improvement on annuity value: the effect is first positive then negative with the increase of variation of investment $(\sigma)$. Therefore, we separate the $\sigma$ into two intervals $(\sigma \geqslant 0.5$ and $\sigma<0.5)$, set these three parameters in three different levels respectively (see Table 3), consider different combinations of them, and form nine groups of different schemes using an expanded table.

\footnotetext{
${ }^{11}$ We thank one of this paper's reviewers for raising this important issue.
} 
Table 4 Comparison of relative payment risks (Male)

\begin{tabular}{|c|c|c|c|c|}
\hline$T$ & 10 & 20 & 30 & 40 \\
\hline \multicolumn{5}{|c|}{ For equity-linked annuity insurance } \\
\hline$(U I-U) / U$ & 0.0157 & 0.0652 & 0.1637 & 0.2348 \\
\hline $\begin{array}{l}\text { For traditional ann } \\
\left(U I^{(1)}-U^{(1)}\right) / U^{(1)}\end{array}$ & 0.0145 & 0.0543 & 0.1205 & 0.1590 \\
\hline
\end{tabular}

Assumptions: $D=1, x=60, t=2003, \sigma=0.12, r=0.02, r_{g}=0.03^{2}$.

Based on Table 3, we find that the annuity values are very sensitive to changes in the risk-free interest rates, and most insensitive to changes in the variation of investment returns when several parameters change simultaneously. The sensitivities of variation of investment returns to the effects of mortality improvement on annuity values are greater when $\sigma \geqslant 0.5$ than when $\sigma<0.5$.

\section{Comparison between equity-linked annuity insurance and traditional annuity insurance}

The single benefit premium of traditional annuity insurance is

$$
U^{(1)}=\sum_{i=1}^{T}{ }_{i} p_{x} e^{-r i}
$$

The single benefit premium of traditional annuity insurance considering mortality improvement is

$$
U I^{(1)}=\sum_{i=1}^{T}{ }_{i} p_{x}(t+k) e^{-r i}
$$

where

$$
{ }_{i} p_{x}(t+k)=\prod_{k=0}^{i}\left(1-q_{x+k}(t+k)\right)
$$

Table 4 and Figure 5 display the change patterns of relative payment risks with change of insurance terms for equity-linked annuities and for traditional annuities (male cases). We find that for both equity-linked annuities and traditional annuities, the relative payment risks on annuity values increase with the increase of insurance term $(T)$. However, this effect is smaller for traditional annuities than that for equitylinked annuities and the difference of sensitivity is further expanded with the increase of $T$. One reason might be that for equity-linked annuity insurance, the amount paid to those who live longer is greater. Another reason might be that the overall uncertainty increases as the holding period increases, thus total returns become more uncertain. Of course, other factors, such as returns and interest rates, will also affect 


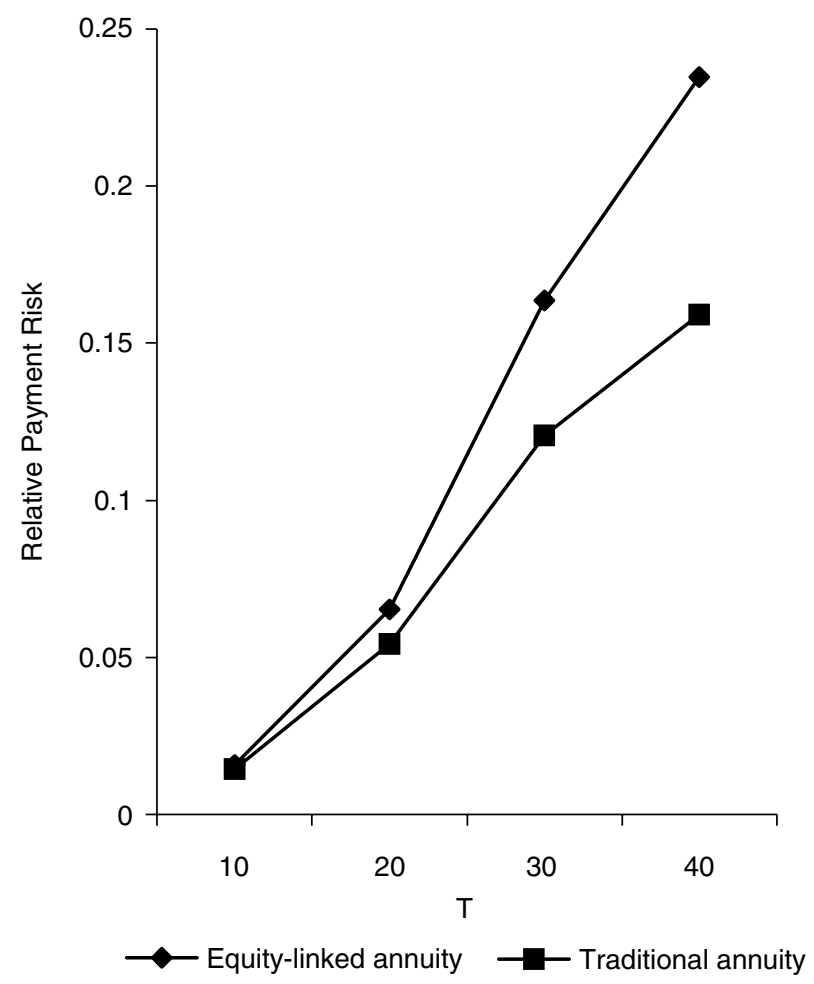

Figure 5. Effects of mortality improvement on annuity values under different holding periods (Male). Assumptions: $D=1, x=60, t=2003, \sigma=0.12, r=0.02, r_{g}=0.03$.

the annuity value. Further research is warranted in the area of comparative analysis of all of these factors.

Figure 6 shows change patterns in the effects of mortality improvement on annuity values for traditional annuity and equity-linked annuity (female cases) when the riskfree interest rate changes. The figure shows that the sensitivity of the effect of mortality improvement on annuity value with the changes in the risk-free interest rate is much smaller for equity-linked annuities than for traditional annuities. Also, the sensitivity of the effect of mortality improvement on annuity value with the changes of investment standard deviation is quite small for equity-linked annuity insurance. The results of robustness to interest rate and investment standard deviation indicate that we can estimate the risk value of mortality improvement for equity-linked annuities even though the interest rate and investment standard deviation cannot be determined accurately. In addition, the equity-linked annuity risk level drops to an almost flat level when the risk-free interest rate is well above the minimum guaranteed rate. This further supports Table 2 results: when $r>r_{g}$, the guarantee loses its value and there is almost no investment risk left that the insurer must bear. The risk that is left, that is, the almost constant flat level of it, is partly attributed to potential mortality 


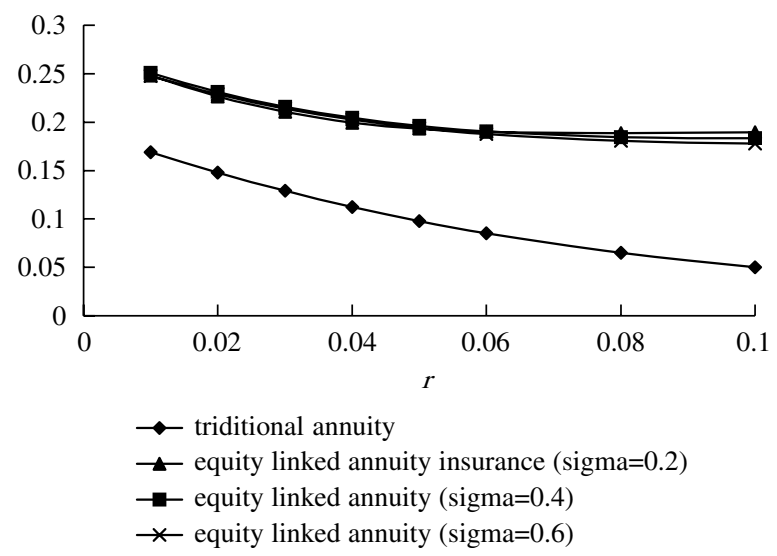

Figure 6. Effects of mortality improvement on annuity values under different interest rates (Female). Assumptions: $D=1, x=60, t=2003, r_{g}=0.03, T=40$.

improvement. But we should also note that for the same interest rate, the relative payment risk for traditional annuity insurance is much smaller than that for equitylinked annuity. We plan to investigate this further.

\section{Managing the mortality improvement risk}

The annuity products with some guaranteed death benefits contain features that alleviate some financial consequences of mortality improvement risk. This section introduces two such products and shows how they reduce the insurer's mortality improvement risk. Before we proceed, let us consider the following simple insurance product: a life annuity, paying a unit benefit as long as the insured is alive, and paying a death benefit equal to the market value of a unit perpetuity (paid in the same fashion as the life annuity) upon the death of the insured. This simplified product has no mortality risk and no mortality improvement risk: its market value is always equal to the current market value of a level perpetuity paid in the same fashion as the life annuity. This elimination of mortality risk is achieved by combining life annuity and life insurance in one product on the same life. One can argue that the life insurance product acts as a natural hedge for the life annuity mortality risk in this context. There are, however, features of this product that are difficult to implement in the real life risk management by an insurance firm:

- This product assumes that the death benefit of the life insurance portion of the policy is perfectly coordinated with the market value of the life annuity portion of the policy, while in real life the death benefit of a life insurance policy is predetermined at the onset of the contract.

- This product assumes that both the life insurance portion and the life annuity portion of the contract are both issued on the same life. In practice, imposing such a condition on policies would result in great limitations for the marketing of a 
company's products and may be a self-defeating strategy. On the other hand, if lives insured in the life annuity portion of the policy are different than lives insured under the life insurance portion of the policy, management of the risk of mortality improvement becomes significantly more complicated. In a realistic setting, in a block of life annuity policies, in a competitive market, customers may transfer their policies to other providers, and customers also self-select for life annuity coverage. With greater access to private information about their health, healthy customers are more likely to purchase life annuity than those who know their life span is limited. Purchase of life annuity requires some, or even substantial, wealth, and wealth is positively correlated with longevity, resulting again in anti-selection in the purchase decision. Finally, in a competitive market, consumers with a limited life span may seek to transfer their annuities to companies that offer them higher payouts based on pooling of only high mortality consumers (e.g., companies offer higher life annuities to smokers than to non-smokers). On the other hand, in the life insurance pool, consumers with lower mortality are less likely to purchase life insurance, more likely to be wealthy and self-insure, and more likely to leave the insured pool in pursuit of cheaper coverage elsewhere. All of these factors result in anti-selection against the insurer on both the life insurance side and the life annuity side, and that anti-selection is likely to become more pronounced in the presence of mortality improvement.

The hedge for life annuity offered by life insurance business is therefore a natural one, but a very difficult one to implement in a realistic business environment. Nevertheless, we believe this idea does deserve consideration. We present our analysis now.

\section{Life annuity with guaranteed death benefits}

A life annuity with guaranteed death benefits will pay a certain amount of death benefits if the annuitant dies early. The single benefit premium for such a product (assuming unit benefit) can be calculated as

$$
V^{(1)}=\sum_{i=1}^{T}\left({ }_{i} p_{x}+q_{x+i-1}\right) e^{-r i} .
$$

The single premium of life annuity with guaranteed death benefits considering mortality improvement is

$$
V I^{(1)}=\sum_{i=1}^{T}\left({ }_{i} p_{x}(t+k)+q_{x+i-1}(t+k)\right) e^{-r i}
$$

where,

$$
\begin{aligned}
{ }_{i} p_{x}(t+k) & =\prod_{k=0}^{i}\left(1-q_{x+k}(t+k)\right) \\
q_{x+i}(t+k) & =q_{x+i}(t) R_{x}(t+k) .
\end{aligned}
$$

Then, $V I^{(1)}-V^{(1)} / V^{(1)}$ can be used as a measure of relative risk of mortality improvement of life annuity with guaranteed death benefits. 


\section{Variable annuity}

Variable annuity is often considered to be an inflation hedge (as opposed to a fixed annuity, whose fixed interest rate is subject to inflation risk), or an investment vehicle with certain investment guarantees. Commonly, a guaranteed death benefit is offered to protect the loss of principal due to market declines when an annuitant dies before retirement. The single premium of variable annuity should reflect two components: annuity payment and death benefit. The annuity payments are not fixed and vary with investment performance (typically common stocks, although variables annuities based on any investment portfolio can be offered). The death benefits are usually determined as a function of these two amounts: the amount invested and the value of account on death. Most commonly, the death benefit is the higher of the two. The single premium for variable annuity can be calculated as

$$
\begin{aligned}
V= & \sum_{i=1}^{T}\left({ }_{i} p_{x}+q_{x+i-1}\right) D e^{\left(r_{g}-r\right) i}\left(1-\Phi\left(B_{i}\right)\right) \\
& +D \sum_{i=1}^{T}\left({ }_{i} p_{x}+q_{x+i-1}\right) \Phi\left(A_{i}\right)
\end{aligned}
$$

where $\Phi$ is the cumulative distribution function of a standard normal distribution and

$$
\begin{aligned}
A_{i} & =\frac{\ln \left(e^{-r_{g} i}\right)+\left(r+\frac{1}{2} \sigma^{2}\right) i}{\sigma \sqrt{i}} \\
B_{i} & =A_{i}-\sigma \sqrt{i} \\
{ }_{i} p_{x} & =\prod_{k=1}^{i}\left(1-q_{x+k}(t)\right)
\end{aligned}
$$

The single premium of variable annuity considering mortality improvement can be calculated as

$$
\begin{aligned}
V I= & \sum_{i=1}^{T}\left({ }_{i} p_{x}(t+k)+q_{x+i-1}(t+k)\right) D e^{\left(r_{g}-r\right) i}\left(1-\Phi\left(B_{i}\right)\right)+ \\
& +D \sum_{i=1}^{T}\left({ }_{i} p_{x}(t+k)+q_{x+i-1}(t+k)\right) \Phi\left(A_{i}\right)
\end{aligned}
$$

Similarly, $V I-V / V$ can be seen as relative payment risk for variable annuity subject to mortality improvement.

Table 5 shows the comparison results of relative payment risks of variable annuity, life annuity with guaranteed death benefits, equity-linked annuity and traditional annuity (female cases). It shows that both life annuity with guaranteed death benefits and variable annuity show good results in hedging mortality improvement risk. Especially, for variable annuity, mortality improvement risk is reduced to almost zero when the interest rate is equal to or larger than 0.05. Equity-linked annuity does not have too much effect on mortality improvement. Traditional annuity performs better when the interest rate goes higher. 
Table 5 Relative payment risks (Female)

\begin{tabular}{lcccccccc}
\hline$r$ & 0.01 & 0.02 & 0.03 & 0.04 & 0.05 & 0.06 & 0.08 & 0.10 \\
\hline$(V I-V) / V$ (variable annuity) & 0.1396 & 0.0990 & 0.0573 & 0.0213 & -0.0041 & -0.0191 & -0.03 & -0.032 \\
$\left(V I^{(1)}-V^{(1)}\right) / V^{(1)}$ (life annuity with & 0.1260 & 0.1119 & 0.0990 & 0.0872 & 0.0767 & 0.0674 & 0.0519 & 0.0401 \\
guaranteed death benefits) & & & & & & & & \\
$(U I-U) / U$ (equity-linked annuity) & 0.2462 & 0.2218 & 0.2050 & 0.1954 & 0.1912 & 0.1902 & 0.1911 & 0.1919 \\
$\left(U I^{(1)}-U^{(1)}\right) / U^{(1)}$ (traditional annuity) & 0.1690 & 0.1478 & 0.1290 & 0.1125 & 0.0980 & 0.854 & 0.0651 & 0.0499 \\
\hline
\end{tabular}

Assumptions: $D=1, x=60, t=2003, \sigma=0.12, r_{g}=0.03, T=40$.

Although these products have not traditionally existed in China, the Chinese Regulatory Committee has cancelled its regulation for product design, and insurance companies can freely design and choose products. Therefore, we believe that these products will appear in Chinese insurance market in the near future.

\section{Conclusions}

In this paper, we addressed mortality improvement risk for insurance companies using Chinese Life Table. The model of mortality improvement is proposed in order to forecast the trends of mortality improvement. Models for calculation of relative risk of mortality improvement for two products of equity-linked annuity insurance and traditional annuity insurance are established and comparisons between these two products are presented. Our results show that the relative risk of mortality improvement for equity-linked annuity insurance is greater than that for traditional annuity insurance and the longer the insurance term, the greater the difference is. However, the sensitivity of the effect of mortality improvement on annuity value is much smaller for equity-linked annuity insurance than that for traditional annuity insurance with respect to the change of interest rates and investment returns. Finally, two annuity products with some guaranteed death benefits, life annuity with guaranteed death benefits and variable annuity, are considered for management of mortality improvement risk. Variable annuity has the most remarkable effects on hedging this risk. Future studies should analyze the effects of mortality improvement on annuity values under the assumption of stochastic interest rate and stochastic investment returns.

When insurance companies capitalize on growth in annuity products in the Chinese market, they cannot neglect the adverse effects of mortality improvement. The effect of mortality improvement may be strong enough to influence not just profitability but also the solvency of insurance companies. Further studies should also observe consumers' behavior as mortality improvement risk occurs.

\section{References}

Andreev, K. and Vaupel, J. (2005) Patterns of mortality improvement over age and time in developed countries: Estimation, presentation and implications for mortality forecasting, working paper dated February 12, 2005.

Bacinello, A.R. and Orut, F. (1993) 'Pricing equity-linked life insurance with endogenous minimum guarantees', Insurance: Mathematics and Economics 12: 245-257. 
Boardman, T. (2006) 'Annuitization lessons from UK: money-back annuities and other development', Journal of Risk and Insurance 73: 633-646.

Cairns, A.J., Blake, D., Dawson, P. and Dowd, K. (2005) 'Pricing the Risk on Longevity Bonds', Life and Pensions (October): 41-44.

Keyfitz, N. (1991) 'Experiments in projection of mortality', Canadian Studies in Population 12(2): 1-17.

Lee, R. (1998) 'Probabilistic approaches to population forecasting', Population and Development Review 24: 156-190 (Lutz, Vaupel, and Ahlburg eds.), Supplement: Frontiers of Population Forecasting.

Lin, F.L.F., Lin, T.-M. and Wu, H.-J. (2003) 'A comparison of the impact of mortality improvement trends on annuity pricing among Taiwan, Japan, and Sweden', Journal of Demography 27: 37-66.

MacMinn, R.D., Ostaszewski, K.M., Thiagarajah, R. and Weber, J.F. (2005) An Investigation of Select Birth Cohorts, Presented at the Living to 100 and Beyond Symposium, sponsored by the Society of Actuaries, Orlando, Florida, 12-14 January 2005.

MacMinn, R.D., Ostaszewski, K.M., Thiagarajah, R. and Weber, J.F. (2006) Mortality improvement select birth cohorts and their effect on pricing of survivor bonds, working paper sponsored by the Society of Actuaries.

Olshansky, S.J. (1988) 'On forecasting mortality', The Milbank Quarterly 66(3): 482-530.

Oeppen, J. and Vaupel, J.W. (2002) 'Broken limits to life expectancy', Science 296: 1029-1031.

Pollard, J.H. (1987) 'Projection of age-specific mortality rates', Population Bulletin of the United Nations (21-22): 55-69.

Tabeau, E., Jeths, A. and Heathcote, C. (2001) Forecasting Mortality in Developed Countries, Dordrecht: Kluwer Academic Publishers.

Willets, R. (1999) Mortality in the Next Millennium, paper presented to the Staple Inn Actuarial Society. Willets, R. (2004) The Cohort Effect: Insights and Explanations, paper presented to the Faculty of Actuaries, March 15 2004, and to the Institute of Actuaries, April 26 2004. Printed by Bell \& Bain Ltd., Glasgow. Zhao, Z. and Kinfu, Y. (2005) 'Mortality transition in East Asia', Asian Population Studies 1: 3-30.

\section{About the Authors}

Krzysztof Ostaszewski is a native of Lodz, Poland. He received a Master degree in mathematics from the University of Lodz in 1980, and a Ph.D. in mathematics from the University of Washington in Seattle in 1985. He is a 1991 Chartered Financial Analyst, a 1994 Member of the American Academy of Actuaries, and a 1999 Fellow of the Society of Actuaries. He was a 1995 Fulbright Research Fellow in Poland, studying actuarial aspects of free market reforms, and a Fulbright Senior Specialist in 2003-2004. He is now a Professor of Mathematics and the Actuarial Program Director at Illinois State University. He has authored or co-authored two research monographs in mathematics published by the American Mathematical Society, and four research books in actuarial science: two published by the Society of Actuaries, one with Elsevier, and one with Wydawnictwa Naukowo-Techniczne in Poland as well as several other books, including five volumes of poetry.

Yuling Wang is a doctoral candidate in Risk Management/Insurance (RMI) with a support area in Finance at Florida State University (FSU). She has received a Master degree in Finance from the University of Nebraska-Lincoln.

Hong Mao is an Associate Professor at the School of Economics and Management at Shanghai Second Polytechnic University. During her teaching years, she has got many honors including Distinguished Teacher of Shanghai Municipal, Distinguished Teacher of Shanghai Second Polytechnic University, and Distinguished Teacher Most Liked by Students. Her papers have got first-class and second-class awards conferred by Shanghai Second Polytechnic University. 